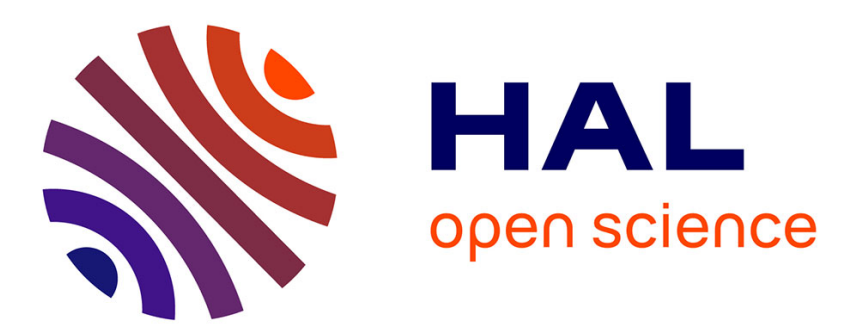

\title{
No evidence of direct binding between ursodeoxycholic acid and the p53 DNA-binding domain
}

Joana D Amaral, Ana R Correia, Clifford J Steer, Cláudio M. Gomes, Cecilia

Mp Rodrigues

\section{- To cite this version:}

Joana D Amaral, Ana R Correia, Clifford J Steer, Cláudio M. Gomes, Cecilia Mp Rodrigues. No evidence of direct binding between ursodeoxycholic acid and the p53 DNA-binding domain. Bioscience Reports, 2010, 30 (5), pp.359-364. 10.1042/BSR20090107 . hal-00488812

\section{HAL Id: hal-00488812 https://hal.science/hal-00488812}

Submitted on 3 Jun 2010

HAL is a multi-disciplinary open access archive for the deposit and dissemination of scientific research documents, whether they are published or not. The documents may come from teaching and research institutions in France or abroad, or from public or private research centers.
L'archive ouverte pluridisciplinaire HAL, est destinée au dépôt et à la diffusion de documents scientifiques de niveau recherche, publiés ou non, émanant des établissements d'enseignement et de recherche français ou étrangers, des laboratoires publics ou privés. 


\section{No evidence of direct binding between ursodeoxycholic acid and the p53 DNA-binding domain}

Joana D. Amaral*1, Ana R. Correia ${ }^{1}{ }^{1}$, Clifford J. Steer $§$, Cláudio M. Gomes ${ }^{\dagger}$, Cecília M. P. Rodrigues ${ }^{2}$

*Research Institute for Medicines and Pharmaceutical Sciences, Faculty of Pharmacy, University of Lisbon, Lisbon, Portugal; †Instituto de Tecnologia Química e Biológica, Universidade Nova de Lisboa, Oeiras, Portugal; and \$Departments of Medicine, and $\S$ Genetics, Cell Biology, and Development, University of Minnesota Medical School, Minneapolis, Minnesota, U.S.A.

Running title: UDCA and p53 DBD binding

${ }^{1}$ Equally contributing authors

${ }^{2}$ Address correspondence to this author at the Research Institute for Medicines and Pharmaceutical Sciences, Faculty of Pharmacy, University of Lisbon, Av. Prof. Gama Pinto, 1649-003 Lisbon, Portugal. Telephone: +351 217946 400; Fax: +351 217946 491; E-mail: cmprodrigues@ff.ul.pt 


\section{Synopsis}

Ursodeoxycholic acid (UDCA) is used increasingly for the treatment of cholestatic liver diseases. Among other cytoprotective effects, this endogenous bile acid is a potent inhibitor of apoptosis, interfering with both intrinsic and extrinsic apoptotic pathways. In previous studies, we have demonstrated that transforming growth factor $\beta 1$-induced E2F-1/Mdm-2/p53 apoptotic pathway was an upstream molecular target of UDCA. In agreement with this, we have recently established p53 as a key molecular target in UDCA prevention of cell death. The tumor suppressor p53 is a well described transcription factor that induces the expression of multiple different proapoptotic gene products. Its regulation involves a variety of signalling proteins and small molecules, and occurs at multiple levels, including transcription, translation, and posttranslation levels. In this study, by using different biophysical techniques, we have investigated the possibility of a direct interaction between the p53 core domain, also referred to as the DNA binding domain, and UDCA. Our in vitro analysis did not provide any evidence for direct binding between the bile acid UDCA and the p53 core domain.

Keywords: Apoptosis - Binding - Circular dichroism - Mdm-2 - p53 - UDCA

Abbreviations: CD, circular dichroism; DBD, DNA binding domain; DTT, dithiothereitol; FITC, fluorescein isothiocyanate ; IPTG, isopropyl- $\beta$-D-thiogalactoside; Mdm-2, mouse double minute 2; NSR, nuclear steroid receptors; TAD, transactivation domain; TGF- $\beta 1$, transforming growth factor $\beta 1 ; \mathrm{T}_{\mathrm{m}}$, temperature of melting; UDCA, ursodeoxycholic acid. 


\section{INTRODUCTION}

The tumor suppressor protein p53 is a transcription factor that functions to maintain genome integrity. It exerts its role by inducing or repressing the expression of a network of genes involved in cell cycle control, senescence, and apoptosis, in response to diverse stress stimuli [1]. Although there is evidence that p53 can mediate apoptosis by transcription-independent mechanisms [2-4], numerous apoptotic genes are transcriptionally activated by this tumor suppressor. These include members of the Bcl2 family, such as Bax, or the BH3-only proteins Noxa and Puma [5-7]. The regulatory functions of p53 are usually under tight control. In normal cells, due to p53 constitutive ubiquitination by Mdm-2, an E3 ligase that targets p53 to proteasomal degradation its levels are almost undetectable [8]. Posttranslational modifications, such as phosphorylation, acetylation, sumoylation, among others are also important mechanisms for $\mathrm{p} 53$ regulation [9].

p53 complexity starts in its structure. The protein is only active when it forms a tetramer and the structure and dynamics of this oligomeric form is crucial to understand its function. In addition, the monomer itself is already complex. It has 393 aminoacid residues that can be divided into 3 functional domains: the $\mathrm{N}$-terminal domain (1-93), an intrinsically disordered region that includes the transactivation domain (TAD) and the proline-rich region, the DNA-binding domain (DBD) (102-292), a structured region that constitutes the proteins core, and finally the C-terminal domain that includes two small domains, a tetramerization domain that regulates the oligomerization state of p53 (320-356), and a natively unfolded regulatory domain (363-393) that binds DNA nonspecifically [10].

Ursodeoxycholic acid (UDCA) is an endogenous hydrophilic bile acid, widely used in the treatment of certain cholestatic disorders of the liver. The therapeutic effects of UDCA may result, in part, from its ability to inhibit liver cell apoptosis. It has been demonstrated that this bile acid plays a unique role in modulating the apoptotic threshold in both hepatic and nonhepatic cells, in response to a variety of agents acting through different apoptotic pathways [11]. The precise mechanism(s) by which UDCA prevents cell death remains speculative and involves molecular targets other than mitochondria. Previous studies indicated that UDCA inhibits the E2F-1/Mdm-2/p53 apoptotic cascade induced by transforming growth factor $\beta 1$ (TGF- $\beta 1)[12,13]$. The ability of E2F-1 to induce apoptosis involves stabilization of p53 via transcription of p14ARF, which markedly inhibits the p53 repressor, Mdm-2 [14]. UDCA, in turn, counteracts TGF- $\beta 1$ effect modulating the expression of apoptosis-related p53 target genes. Further, we demonstrated that UDCA protects hepatocytes from p53-mediated apoptosis, by reducing p 53 transcriptional and DNA-binding activities, possibly through mechanisms involving Mdm-2 [15]. Importantly, UDCA can reach the nucleus where it may interfere with several nuclear proteins, such as E2F-1 or p53 itself, a mechanism that appears to be dependent on nuclear steroid receptors (NSR) [16]. In fact, we and others have shown that UDCA and its taurine-conjugated derivative, tauroursodeoxycholic acid, interact with NSR [16-18]. More importantly, these bile acids promote dissociation of NSR from their cytosolic chaperone, Hsp90, and translocate into the nucleus as a ligand-receptor complex to reduce apoptosis.

In the present study, we have used complementary biophysical techniques to determine whether UDCA binds to or alters the structural stability and folding properties of the p53 DBD. UDCA could compromise p53 function either by destabilizing its structure or by inducing structural fluctuations that could inhibit its DNA-binding specificity. Previously, this approach has been successfully used to 
establish the effect of small peptides (CDB3) on p53 oncogenic mutants [19]; biophysical techniques such as fluorescence anisotropy and differential scanning calorimetry were used to establish that CDB3 binds to p53 DBD rescuing p53 oncogenic mutants. Here we aim to investigate whether UDCA binds to p53 DBD and if so if this alters the stability or conformation of this p53 domain. 


\section{EXPERIMENTAL}

\section{Materials and plasmids}

Chemicals, reagents and enzymes were of the highest purity grade commercially available. Chromatography materials were from Amersham Pharmacia Biotech (Uppsala, Sweden). For protein expression, p53 DBD plasmid coding for amino acids 94-312 of human wild-type p53 was transformed into E.coli BL21 competent cells.

\section{Gene expression and protein}

The DBD of p53 was expressed as soluble protein as described by Bell et al. [20]. In brief, bacteria were grown in Luria-Bertani medium supplemented with $100 \mu \mathrm{g} / \mathrm{ml}$ ampicilin, at $37^{\circ} \mathrm{C}$, to an $\mathrm{A}_{600}$ of 0.5 followed by overnight induction at $22^{\circ} \mathrm{C}$ with $1 \mathrm{mM}$ isopropyl- $\beta$-D-thiogalactoside (IPTG). After induction, cells were harvested by centrifugation, resuspended in $50 \mathrm{mM}$ Tris- $\mathrm{HCl}, \mathrm{pH} 6.8,5 \mathrm{mM}$ dithiothereitol (DTT), 1 $\mathrm{mM}$ benzamidine, complete protease inhibitor tablets (Complete $^{\mathrm{TM}}$; Roche Applied Science, Mannheim, Germany), 200 units of benzonase (Merck, Darmstadt, Germany), and disrupted by high-pressure dispersion using a Thermo IEC French Press (Needham Heights, MA). Purification of p53 DBD was performed at $4^{\circ} \mathrm{C}$ using a combination of cation exchange chromatography on a HiTrap SP Fast Flow column and affinity chromatography on a Heparin HiTrap column (GE Healthcare Life Sciences, Freiburg,

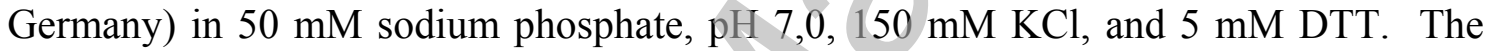
purity of the protein was confirmed by sodium dodecyl sulfate-polyacrylamide gel electrophoresis (Figure 1). p53 DBD was found to be stable in solution and maintained its spectroscopic properties and melting temperature after flash-freezing in liquid nitrogen. Protein concentration was determined spectrophotometrically by using the extinction coefficient of 0.649 for p53 DBD calculated for a $1 \mathrm{mg} / \mathrm{ml}$ solution in a $1 \mathrm{~cm}$ cuvette at $280 \mathrm{~nm}$.

\section{Spectroscopic methods}

Anisotropy measurements were performed at $10^{\circ} \mathrm{C}$, using a SLM Aminco spectrofluorimeter (Spectronic Instruments, Inc., Rochester, NY) with cell stirring. FarUV circular dichroism (CD) spectra were recorded typically at $0.2 \mathrm{~nm}$ resolution on a Jasco J-815 spectropolarimeter (Jasco, Tokyo, Japan) fitted with a cell holder thermostatically controlled by a Peltier.

\section{Thermal denaturation}

Thermal unfolding was followed by monitoring the intrinsic tryptophan fluorescence $\left(\lambda_{\mathrm{em}}=340\right)$ and the ellipticity $\left(\Delta \varepsilon_{\mathrm{mrw}}\right.$ at $\left.222 \mathrm{~nm}\right)$ variations. In all experiments, a heating rate of $1^{\circ} \mathrm{C} / \mathrm{min}$ was used, and the temperature was changed from 10 to $90^{\circ} \mathrm{C}$. Data were analyzed according to a two-state model described by the following equation:

$$
y=\frac{\left(y_{f}+m_{f} \cdot T\right)+\left(y_{u}+m_{w} \cdot T\right) \cdot \exp \left(\frac{\Delta K_{m}}{R T} \cdot \frac{T-T_{m}}{T_{m}}\right)}{1+\exp \left\{\frac{\Delta K_{m}}{R T}, \frac{T-T_{m}}{T_{m}}\right\}}
$$


where $y$ is the spectroscopic signal observed, $m_{\mathrm{f}}$ and $m_{\mathrm{u}}$ are the slopes of the pre- and post-transition baselines, $y_{\mathrm{f}}$ and $y_{\mathrm{u}}$ correspond to the value of $y$ for folded and unfolded forms, $T_{\mathrm{m}}$ is the midpoint of the thermal unfolding curve, and $\Delta H_{\mathrm{m}}$ is the enthalpy change for unfolding at $T_{\mathrm{m}}$. The fits to the unfolding transitions were made using Origin (MicroCal Software Inc, Northampton, MA)

\section{Binding studies}

All measurements were performed with fluorescein isothiocyanate (FITC)-tagged UDCA. The interaction between p53 DBD and FITC-UDCA was evaluated by using both far-UV CD and fluorescence anisotropy spectroscopy, at a constant temperature of $10^{\circ} \mathrm{C}$, in buffer containing $20 \mathrm{mM} \mathrm{NaP}, 50 \mathrm{mM} \mathrm{NaCl}$, and $2 \mathrm{mM}$ DTT, $\mathrm{pH}$ 7.5. Far-UV $\mathrm{CD}$ measurements were performed with $100 \mu \mathrm{M}$ p53 DBD, before and after the addition of the bile acid at stoichiometric ratio 1:1, using a $1 \mathrm{~mm}$ cell path length (bandwidth 2 $\mathrm{nm})$. The spectra were recorded from 260 to $190 \mathrm{~nm}$ and accumulated 10 times. For titration experiments, aliquots of $3 \mu \mathrm{l}$ of titrant $(500 \mu \mathrm{M}$ FITC-UDCA) were sequentially added to p53 DBD peptide in solution $(0.22 \mathrm{mg} / \mathrm{ml})$, until the concentration reached p53 DBD 1:54 UDCA. All spectra were corrected for buffer contributions and protein concentration. Ellipticities were followed at 208 and $222 \mathrm{~nm}$.

For anisotropy experiments, p53 DBD (initial concentration $30 \mu \mathrm{M}$ ) was titrated with FITC-UDCA $(500 \mu \mathrm{M})$ with increments of $5 \mu \mathrm{l}$, waiting $\sim 5$ min between each addition. Similarly, FITC-UDCA (initial concentration $5 \mu \mathrm{M}$ ) was titrated with p53 DBD $(50 \mu \mathrm{M})$, additions of $10 \mu \mathrm{l}$ every $5 \mathrm{~min}$. When the FITC-UDCA was titrated, fluorescence anisotropy was measured on excitation at $480 \mathrm{~nm}$ (bandwith $8 \mathrm{~nm}$ ) and emission at $520 \mathrm{~nm}$ (bandwith $8 \mathrm{~nm}$ ). When the protein was titrated fluorescence anisotropy was measured on excitation at $280 \mathrm{~nm}$ (bandwith $8 \mathrm{~nm}$ ) and emission at 340 $\mathrm{nm}$ (bandwith $8 \mathrm{~nm}$ ). 


\section{RESULTS}

\section{Characterization of p53 DNA-binding domain}

p53 DBD was expressed in E.coli with a low yield of $\sim 3 \mathrm{mg}$ of purified protein per $3 \mathrm{~g}$ of wet culture (Figure 1). The fold and the stability of the purified p53 DBD was evaluated by far-UV CD to confirm that the protein used in the binding assays was correctly folded. The far-UV CD spectrum is shown in Figure 2A and is in agreement with previously published data by Klein et al. [21]. As expected, the far-UV CD spectrum of the DNA binding domain of p53 showed two negative peaks ( 208 and 222 $\mathrm{nm}$ ), which reflect its $\alpha$-helical content. As a result of the $\beta$-sheet contributions, the 208 $\mathrm{nm}$ peak was broader and the $222 \mathrm{~nm}$ peak was less intense. Thermal denaturation following far-UV CD signal at $222 \mathrm{~nm}$, allowed to evaluate the p53 DBD stability (Figure 2B). In agreement with previously published data [20], a melting temperature $\left(T_{\mathrm{m}}\right)$ of $41.5 \pm 0.3^{\circ} \mathrm{C}$ was determined.

\section{Evaluation of UDCA interaction with p53 DNA-binding domain}

To investigate a possible interaction between UDCA and p53 DBD, we used both farUV CD and fluorescence anisotropy to monitor structural changes that might occur as a consequence of bile acid presence. First, we followed the titration of p53 DBD with FITC-UDCA by far-UV CD $(208 \mathrm{~nm}$ and $222 \mathrm{~nm})$. Adding the bile acid has no effect on the protein spectrum, even for a stoichiometry of 1 p53 DBD to 54 FITC-UDCA (Figure 2A and 3A), meaning that FITC-UDCA does not affect the p53 DBD secondary structure. Similarly, the thermal stability of p53 DBD is not significantly affected by the presence of FITC-UDCA. In case of a specific interaction of UDCA with the native conformation of the p53 DBD, a positive $T_{\underline{m}}$ shift would be expected. Our results indicate that the presence of this bile acid induces a $\Delta T_{\mathrm{m}}-3.3 \pm 1{ }^{\circ} \mathrm{C}$ (Figure $2 \mathrm{~B}$ ), which may be considered negligible since FITC-UDCA also significantly reduces the $\underline{\text { signal/noise, thus increasing the uncertainty in the } T_{\underline{m}} \text { determination. Alternatively, this }}$ shift may result from weak unspecific interactions of UDCA with p53 DBD, given the mild detergent properties of UDCA.

Similar titrations were performed following changes in fluorescence anisotropy. Initially, p53 DBD $(30 \mu \mathrm{M})$ was titrated with FITC-UDCA $(500 \mu \mathrm{M})$; however, no changes in p53 fluorescence anisotropy were detected (Figure 3B). The same result was obtained when titrating FITC-UDCA with increasing amounts of p53 DBD (data not shown).

Under the conditions used, it was not possible to detect a direct interaction between anti-apoptotic UDCA and the DNA-binding domain of human p53, in vitro. 


\section{DISCUSSION}

The mechanisms of bile acid effects on cell survival and apoptosis are not entirely understood. We have previously reported that UDCA prevents apoptosis in several cell types by inhibiting the mitochondrial pathway $[11,22,23]$ and modulating the E2F1/Mdm-2/p53 apoptotic cascade $[12,15]$. In addition, bile acids have been detected in nuclei of several cell types [16, 24-26]. We have suggested that UDCA, as a cholesterol-derived molecule, could reach the nucleus through mechanisms similar to those used by steroid hormones. It appears that NSR are specifically required for the nuclear trafficking of UDCA, ultimately protecting cells from undergoing apoptosis [16, 18]. Therefore, it is conceivable that bile acids may act as molecular modulators of apoptosis-related gene expression, by interfering directly with DNA, or by interacting with transcription factors and other nuclear proteins involved in the apoptotic machinery.

p53 has a multidomain structure comprising a folded region with DNA-binding and tetramerization domains, and natively unfolded regions with molecular recognition features that provide binding promiscuity [10]. Since specific binding to p53responsive genes occurs through the DNA-binding domain of $\mathrm{p} 53$, and based on our previous data indicating that UDCA is capable of reducing p53 transcriptional and DNA-binding activities [15], here we have focused on the effect of UDCA in the structure and conformation of p53 DBD.

Two complementary biophysical techniques were used: far-UV CD and fluorescence anisotropy-Far-UV CD spectroscopy is widely used in the study of molecular interactions due to its remarkable sensitivity. Far-UV CD bands derive mainly from peptide bond absorption, reflecting the secondary structure of the protein [27]. Fluorescence anisotropy, in turn, detects the rotational mobility of a fluorophore, which is also a reliable and sensitive spectroscopic method to locally evaluate the existence of physical interactions. Unbounded molecules can freely rotate in solution, while formation of binding structures restricts their motion, thereby increasing anisotropy [28].

Under the conditions tested, neither CD nor fluorescence anisotropy supported the hypothesis of a direct interaction between UDCA and the p53 DBD. CD experiments have shown that the presence of UDCA does not induce changes on the secondary structure of p53 DBD. Similarly, data on fluorescence anisotropy showed no alterations in the mobility of either p53, or UDCA, when together.

UDCA could be interacting with other regions of $\mathrm{p} 53$. The $\mathrm{N}$-terminal region of p53 contains the TAD, considered to be a binding site for a multitude of interacting proteins, such as components of the transcription machinery [29, 30], the transcriptional coactivators $\mathrm{p} 300 / \mathrm{CBP}$ (CREB-binding protein) [31,32], and the negative regulator Mdm-2 [33, 34]. Upon binding, intrinsically disordered regions of the p53 TAD rigidify and become fully folded. This is the case for the p53 fragment comprising residues 15-29 after binding to a hydrophobic cleft in the N-terminus of Mdm-2 [35]. Moreover, it has been reported that Mdm-2 also undergoes extensive conformational changes along its $\mathrm{N}$-terminal region, upon binding to p53 [34]. Interestingly, the Mdm2 protein is the major repressor of $\mathrm{p} 53$, and UDCA has been shown to increase its levels in rat hepatocytes undergoing TGF- $\beta 1$-induced apoptosis [12]. More importantly, the bile acid was shown to play a role in $\mathrm{p} 53 / \mathrm{Mdm}-2$ association during p53-induced hepatocyte apoptosis [15]. Thus, the N-terminus of p53, or more specifically, the TAD domain, could also be a potential target region for UDCA binding/interaction. The bile acid may additionally interact with Mdm-2 itself, in the p53-binding cleft of bounded or 
unbounded Mdm-2, to somehow stabilize the complex. The p53-binding cleft is the most flexible region of the Mdm-2 protein, presenting enough plasticity to adapt to diverse topologies of incoming ligands [36]. In fact, the number of newly discovered small-molecules that bind the Mdm-2-p53 binding cleft is continuously increasing over the years [37-40].

Interaction between UDCA and the extreme C-terminus of p53 should also be analyzed. The C-terminal region of $\mathrm{p} 53$, called regulatory domain, is subjected to extensive posttranslational modifications to regulate p53 function, including acetylation, ubiquitination, phosphorylation, and methylation. Finally, three putative nuclear localization signals [41] and one nuclear export signal [42] sequences have been identified within the C-terminal region of p53. Subcellular localization of $\mathrm{p} 53$ is determinant for its activity, since stabilized p53 remains active in the nucleus, whereas translocation to the cytoplasm is required for Mdm-2-mediated p53 degradation [43]. Thus, UDCA could inhibit the p53 apoptotic pathway not by directly binding to p53 but by interfering with other proteins and molecular pathways involved in the regulation of this complex protein.

The multifaceted network of $\mathrm{p} 53$ regulation opens the door for an endless world of hypothesis in which UDCA could participate and play a role. Although, we could not detect direct binding between the p53 DBD and UDCA, our findings contributed to the characterization of the interaction between these two molecules. 


\section{ACKNOWLEDGEMENTS}

We thank Dr. Christian Klein, Roche Diagnostics GmbH, Penzberg, Germany, for providing the human recombinant p53 DBD expression plasmid, and Dr. Jesse D. Martinez, University of Arizona, Tucson, USA the FITC-UDCA.

\section{FUNDING}

Supported by grants PPCDT/SAU-FCF/62479/2004 and PTDC/SAU-FCF/67912/2006 from Fundação para a Ciência e a Tecnologia (FCT), Lisbon, Portugal (to C.M.P.R.). J.D.A. and A.R.C. were recipients of Ph.D. fellowships (BD/17799/2004 and BD/24949/2005, respectively) from FCT. 


\section{REFERENCES}

1. Riley, T., Sontag, E., Chen, P. and Levine, A. (2008) Transcriptional control of human p53-regulated genes. Nat. Rev. Mol. Cell Biol. 9, 402-412.

2. Schuler, M., Bossy-Wetzel, E., Goldstein, J.C., Fitzgerald, P. and Green, D.R. (2000) p53 induces apoptosis by caspase activation through mitochondrial cytochrome $\mathrm{c}$ release. J. Biol. Chem. 275, 7337-7342.

3. Speidel, D., Helmbold, H. and Deppert, W. (2006) Dissection of transcriptional and nontranscriptional p53 activities in the response to genotoxic stress. Oncogene 25, 940-953.

4. Marchenko, N.D., Wolff, S., Erster, S., Becker, K. and Moll, U.M. (2007) Monoubiquitylation promotes mitochondrial p53 translocation. Embo J. 26, 923-934.

5. Miyashita, T. and Reed, J.C. (1995) Tumor suppressor p53 is a direct transcriptional activator of the human bax gene. Cell 80, 293-299.

6. Oda, E., Ohki, R., Murasawa, H., Nemoto, J., Shibue, T., Yamashita, T., Tokino, T., Taniguchi, T. and Tanaka, N. (2000) Noxa, a BH3-only member of the Bcl-2 family and candidate mediator of p53-induced apoptosis. Science 288, 1053-1058.

7. Nakano, K. and Vousden, K.H. (2001) PUMA, a novel proapoptotic gene, is induced by p53. Mol Cell 7, 683-694.

8. Brooks, C.L., Li, M. and Gu, W. (2007) Mechanistic studies of MDM2-mediated ubiquitination in p53 regulation. J. Biol. Chem. 282, 22804-22815.

9. Ashcroft, M. and Vousden, K.H. (1999) Regulation of p53 stability. Oncogene 18, 76377643.

10. Joerger, A.C. and Fersht, A.R. (2008) Structural Biology of the Tumor Suppressor p53. Annu. Rev. Biochem. 77, 557-582.

11. Rodrigues, C.M., Fan, G., Ma, X., Kren, B.T. and Steer, C.J. (1998) A novel role for ursodeoxycholic acid in inhibiting apoptosis by modulating mitochondrial membrane perturbation. J. Clin. Invest. 101, 2790-2799.

12. Solá, S., Ma, X., Castro, R.E., Kren, B.T., Steer, C.J. and Rodrigues, C.M. (2003) Ursodeoxycholic acid modulates E2F-1 and p53 expression through a caspase-independent mechanism in transforming growth factor $\beta 1$-induced apoptosis of rat hepatocytes. J. Biol. Chem. 278, 48831-48838.

13. Solá, S., Castro, R.E., Kren, B.T., Steer, C.J. and Rodrigues, C.M. (2004) Modulation of nuclear steroid receptors by ursodeoxycholic acid inhibits TGF- $\beta 1$-induced E2F-1/p53-mediated apoptosis of rat hepatocytes. Biochemistry 43, 8429-8438.

14. Phillips, A.C. and Vousden, K.H. (2001) E2F-1 induced apoptosis. Apoptosis 6, 173-182.

15. Amaral, J.D., Castro, R.E., Sola, S., Steer, C.J. and Rodrigues, C.M. (2007) p53 is a key molecular target of ursodeoxycholic acid in regulating apoptosis. J. Biol. Chem. 282, 3425034259.

16. Solá, S., Amaral, J.D., Castro, R.E., Ramalho, R.M., Borralho, P.M., Kren, B.T., Tanaka, H., Steer, C.J. and Rodrigues, C.M. (2005) Nuclear translocation of UDCA by the glucocorticoid receptor is required to reduce TGF- $\beta 1$-induced apoptosis in rat hepatocytes. Hepatology 42, 925934.

17. Tanaka, H. and Makino, I. (1992) Ursodeoxycholic acid-dependent activation of the glucocorticoid receptor. Biochem. Biophys. Res. Commun. 188, 942-948.

18. Solá, S., Amaral, J.D., Borralho, P.M., Ramalho, R.M., Castro, R.E., Aranha, M.M., Steer, C.J. and Rodrigues, C.M. (2006) Functional modulation of nuclear steroid receptors by tauroursodeoxycholic acid reduces amyloid $\{\beta\}$-Peptide-induced Apoptosis. Mol. Endocrinol. 20, 2292-2303.

19. Friedler, A., Hansson, L.O., Veprintsev, D.B., Freund, S.M., Rippin, T.M., Nikolova, P.V., Proctor, M.R., Rüdiger, S., Fersht, A.R. (2002) A peptide that binds and stabilizes p53 core 
domain: chaperone strategy for rescue of oncogenic mutants.. Proc. Natl. Acad. Sci. U. S. A. 99, 937-942.

20. Bell, S., Klein, C., Muller, L., Hansen, S. and Buchner, J. (2002) p53 contains large unstructured regions in its native state. J. Mol. Biol. 322, 917-927.

21. Klein, C., Georges, G., Kunkele, K.P., Huber, R., Engh, R.A. and Hansen, S. (2001) High thermostability and lack of cooperative DNA binding distinguish the p63 core domain from the homologous tumor suppressor p53. J. Biol. Chem. 276, 37390-37401.

22. Botla, R., Spivey, J.R., Aguilar, H., Bronk, S.F. and Gores, G.J. (1995) Ursodeoxycholate (UDCA) inhibits the mitochondrial membrane permeability transition induced by glycochenodeoxycholate: a mechanism of UDCA cytoprotection. J. Pharmacol. Exp. Ther. 272, 930-938.

23. Rodrigues, C.M., Ma, X., Linehan-Stieers, C., Fan, G., Kren, B.T. and Steer, C.J. (1999) Ursodeoxycholic acid prevents cytochrome $c$ release in apoptosis by inhibiting mitochondrial membrane depolarization and channel formation. Cell Death Differ. 6, 842-854.

24. Setchell, K.D., Rodrigues, C.M., Clerici, C., Solinas, A., Morelli, A., Gartung, C. and Boyer, J. (1997) Bile acid concentrations in human and rat liver tissue and in hepatocyte nuclei. Gastroenterology 112, 226-235.

25. Kren, B.T., Rodrigues, C.M., Setchell, K.D. and Steer, C.J. (2001) Modulation of steadystate messenger RNA levels in the regenerating rat liver with bile acid feeding. Liver Transpl. 7, 321-334.

26. Monte, M.J., Martinez-Diez, M.C., El-Mir, M.Y., Mendoza, M.E., Bravo, P., Bachs, O. and Marin, J.J. (2002) Changes in the pool of bile acids in hepatocyte nuclei during rat liver regeneration. J. Hepatol. 36, 534-542.

27. Martin, S.R. and Bayley, P.M. (2002) in Methods in Molecular Biology vol 2. CalciumBinding Protein Protocols (Vogel, H. J., ed), pp. 43-55, Humana Press, Totowa, NJ.

28. Royer, C.A. (1995) in Fluorescence Spectroscopy. Protein Stability and Folding: Theory and Practice vol 40 (Shirley, B.A., ed), Humana Press, Totowa, NJ.

29. Lu, H. and Levine, A.J. (1995) Human TAFII31 protein is a transcriptional coactivator of the p53 protein. Proc. Natl. Acad. Sci. U. S. A. 92, 5154-5158.

30. Di Lello, P., Jenkins, L.M., Jones, T.N., Nguyen, B.D., Hara, T., Yamaguchi, H., Dikeakos, J.D., Appella, E., Legault, P. and Omichinski, J.G. (2006) Structure of the Tfb1/p53 complex: Insights into the interaction between the p62/Tfb1 subunit of TFIIH and the activation domain of p53. Mol. Cell 22, 731-740.

31. Antonsson, B., Conti, F., Ciavatta, A., Montessuit, S., Lewis, S., Martinou, I., Bernasconi, L., Bernard, A., Mermod, J.J., Mazzei, G., Maundrell, K., Gambale, F., Sadoul, R. and Martinou, J.C. (1997) Inhibition of Bax channel-forming activity by Bcl-2. Science 277, 370-372.

32. Teufel, D.P., Freund, S.M., Bycroft, M. and Fersht, A.R. (2007) Four domains of p300 each bind tightly to a sequence spanning both transactivation subdomains of p53. Proc. Natl. Acad. Sci. U. S. A. 104, 7009-7014.

33. Kussie, P.H., Gorina, S., Marechal, V., Elenbaas, B., Moreau, J., Levine, A.J. and Pavletich, N.P. (1996) Structure of the MDM2 oncoprotein bound to the p53 tumor suppressor transactivation domain. Science 274, 948-953.

34. Schon, O., Friedler, A., Bycroft, M., Freund, S.M. and Fersht, A.R. (2002) Molecular mechanism of the interaction between MDM2 and p53. J. Mol. Biol. 323, 491-501.

35. Popowicz, G.M., Czarna, A., Rothweiler, U., Sszwagierczak, A., Krajewski, M., Weber, L. and Holak, T.A. (2007) Molecular basis for the inhibition of p53 by Mdmx. Cell Cycle 6,

36. Espinoza-Fonseca, L.M. and Trujillo-Ferrara, J.G. (2006) Conformational changes of the p53-binding cleft of MDM2 revealed by molecular dynamics simulations. Biopolymers 83, 365373. 
37. Vassilev, L.T., Vu, B.T., Graves, B., Carvajal, D., Podlaski, F., Filipovic, Z., Kong, N., Kammlott, U., Lukacs, C., Klein, C., Fotouhi, N. and Liu, E.A. (2004) In vivo activation of the p53 pathway by small-molecule antagonists of MDM2. Science 303, 844-848.

38. Grasberger, B.L., Lu, T., Schubert, C., Parks, D.J., Carver, T.E., Koblish, H.K., Cummings, M.D., LaFrance, L.V., Milkiewicz, K.L., Calvo, R.R., Maguire, D., Lattanze, J., Franks, C.F., Zhao, S., Ramachandren, K., Bylebyl, G.R., Zhang, M., Manthey, C.L., Petrella, E.C., Pantoliano, M.W., Deckman, I.C., Spurlino, J.C., Maroney, A.C., Tomczuk, B.E., Molloy, C.J. and Bone, R.F. (2005) Discovery and cocrystal structure of benzodiazepinedione HDM2 antagonists that activate p53 in cells. J. Med. Chem. 48, 909-912.

39. Dudkina, A.S. and Lindsley, C.W. (2007) Small molecule protein-protein inhibitors for the p53-MDM2 interaction. Curr. Top. Med. Chem. 7, 952-960.

40. Dey, A., Verma, C.S. and Lane, D.P. (2008) Updates on p53: modulation of p53 degradation as a therapeutic approach. Br. J. Cancer 98, 4-8.

41. Liang, S.H. and Clarke, M.F. (1999) A bipartite nuclear localization signal is required for p53 nuclear import regulated by a carboxyl-terminal domain. J. Biol. Chem. 274, 32699-32703.

42. Stommel, J.M., Marchenko, N.D., Jimenez, G.S., Moll, U.M., Hope, T.J. and Wahl, G.M. (1999) A leucine-rich nuclear export signal in the p53 tetramerization domain: regulation of subcellular localization and p53 activity by NES masking. Embo J. 18, 1660-1672.

43. O'Keefe, K., Li, H. and Zhang, Y. (2003) Nucleocytoplasmic shuttling of p53 is essential for MDM2-mediated cytoplasmic degradation but not ubiquitination. Mol. Cell Biol. 23, 6396-6405. 


\section{FIGURE LEGENDS}

Figure 1 Purity of p53 DNA-binding domain. p53 DBD purified from E.coli bacteria was subjected to electrophoresis on $12.5 \%$ polyacrylamide gels and stained with Coomassie brilliant blue.

Figure 2 Effect of UDCA in the structural properties of p53 DNA-binding domain. (A) FarUV CD spectra of p53 DBD $(0.22 \mathrm{mg} / \mathrm{ml})$, with or without UDCA. (B) Far-UV CD analysis of thermal denaturation transitions of p53 DBD alone $(\boldsymbol{\square})$, or in the presence of UDCA ( $\square)$. See "Experimental" for details.

Figure 3 Titration of p53 DBD with FITC-UDCA. Titration of p53 DBD protein with increasing amounts of FITC-UDCA, analyzed by far-UV CD (A) or fluorescence anisotropy spectroscopy (B). See "Experimental" for details. 


\section{FIGURES}

Figure 1

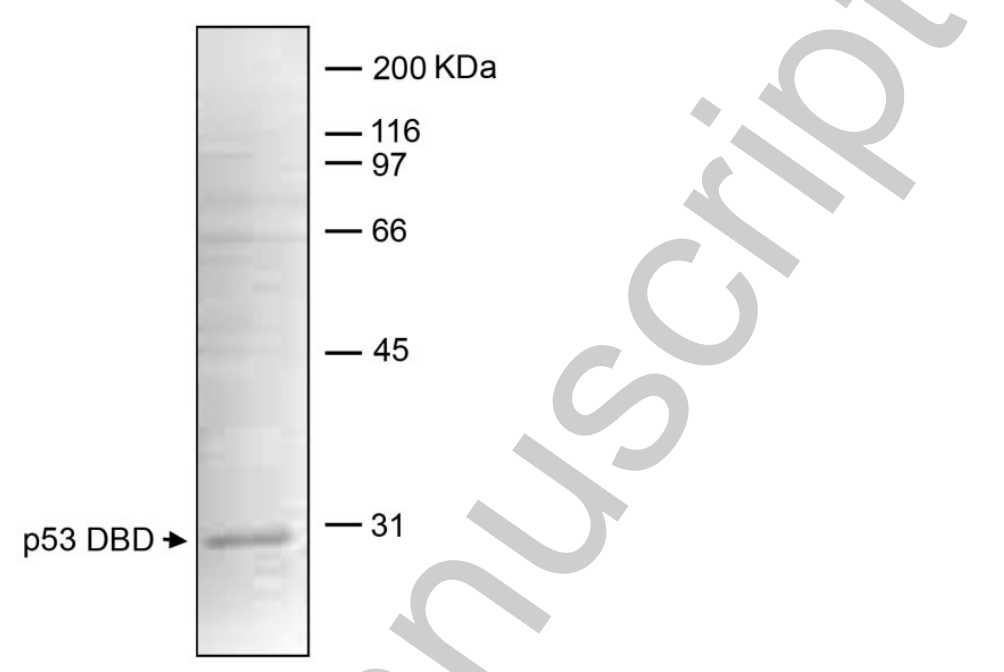


Figure 2

A

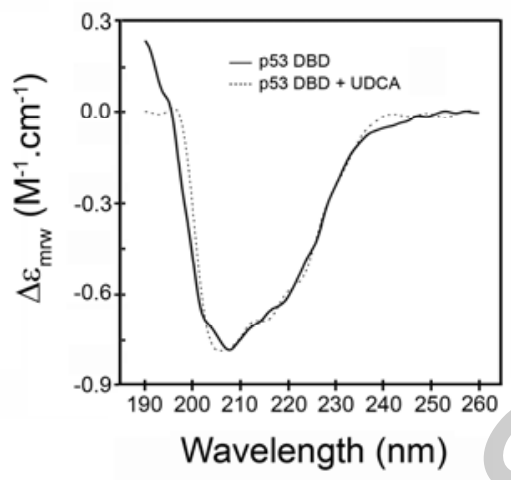

B

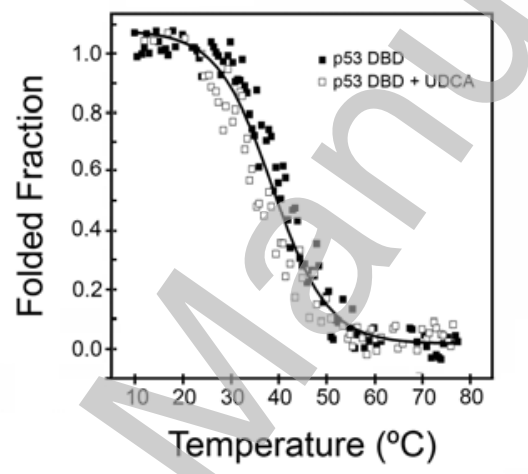


Figure 3

A

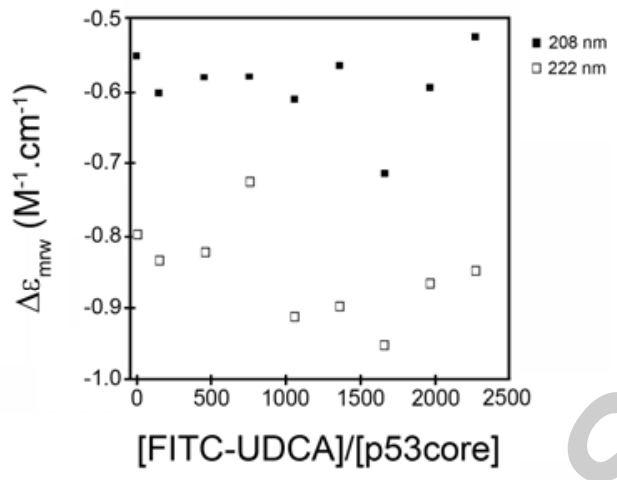

B

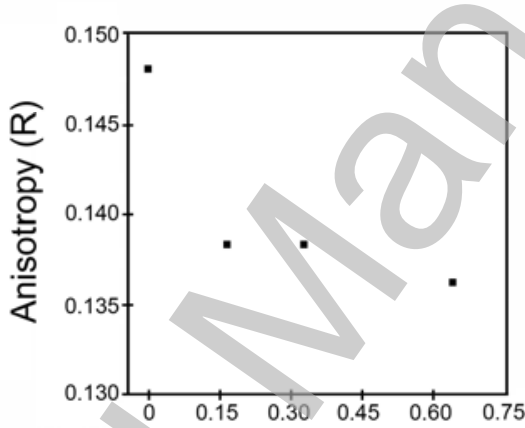

[FITC-UDCA]/[p53core] 